\title{
Influence of the Rewards and Recognition Scheme on Higher Vocational Education Curriculum Reform in China
}

\author{
Hao Chen ${ }^{1}$, Mark Tyler $^{1} \&$ Richard G. Bagnall ${ }^{1}$ \\ ${ }^{1}$ School of Education and Professional Studies, Griffith University, Queensland, Australia \\ Correspondence: Hao Chen, School of Education and Professional Studies, Griffith University, 176 Messines \\ Ridge Rd, Mount Gravatt 4122, Queensland, Australia.
}

\author{
Received: April 17, $2018 \quad$ Accepted: May 6, $2018 \quad$ Online Published: May 15, 2018 \\ doi:10.5539/jel.v7n4p66 URL: https://doi.org/10.5539/jel.v7n4p66
}

\begin{abstract}
This paper reviews the impact of the rewards and recognition scheme on curriculum reform in higher vocational education (HVE) in China. In this scheme, teachers and students can win rewards and obtain recognition through curriculum competitions and student skill competitions conducted by the government. It has been used to encourage and to support colleges and teachers to implement HVE curriculum reform. The qualitative research project into HVE curriculum reform reported here identified both the facilitative and inhibitory effects of the scheme on curriculum reform. Discipline heads' perspectives of these influences were investigated through in-depth interviews. The scheme was seen as motivating just a slight majority of discipline heads to implement curriculum reform and as providing financial support in doing so. The discipline heads, though, also indicated that they were discouraged by the scheme's misleading guidelines, its inappropriate evaluations of their efforts and its contribution to funding inequalities.
\end{abstract}

Keywords: rewards, recognition, higher vocational education, curriculum reform

\section{Introduction}

In many countries, rewards and recognition schemes have been used to motivate schools, colleges, universities and teachers to improve their practice and performance through offering rewards to those education providers and educators who demonstrate good performance and practice (Harvey-Beavis, 2003; Huggett et al., 2012). Such schemes are promulgated as incentive systems that shape education providers' and teachers' behaviour in ways that will lead to better educational outcomes (Gretton \& Raine, 2015; Ladd, 2011). They have been used particularly to encourage education providers and teachers to adopt educational reforms advocated by government (Hanson, 2003).

Reward and recognition schemes may be seen as grounded in motivation theory, in which rewards and recognition "are something of value that produce pleasure or satisfaction" (Kelley \& Protsik, 1997, p. 475) in those who receive them. They are thus extrinsic incentives, which direct education providers and teachers towards the outcomes specified in the rewards and recognition scheme (King \& Mathers, 1997). By extrinsic incentives in this sense is meant something tangible that is given to someone for accomplishing something, such as monetary rewards and official recognition of accomplishment (Amabile, Hill, Hennessey, \& Tighe, 1994). It contrasts with intrinsic motivation, which has traditionally been seen as motivating teachers and educational providers, and through which they are motivated out of public duty and commitment (King \& Mathers, 1997).

Reward and recognition schemes in education involve incentives, evaluation criteria to assess the performance of schools and teachers, procedures for evaluating performance, and competitions through which high-performing participants are selected and rewarded. Motivating incentives are commonly funds for schools and disciplines, merit pay and career promotion for teachers, accreditation of good practice and performance, and public recognition (Gayles, 2007; King \& Mathers, 1997; K. M. Smith, Else, \& Crookes, 2013). The threat of sanctions or punishments may also be used (King \& Mathers, 1997), with schools and teachers being encouraged to implement educational reforms to avoid unwanted punishment for poor performance. Criteria on which is measured the success of educational reforms have been developed by governments in many countries, such as China, the UK and the USA (Harvey-Beavis, 2003; Huggett et al., 2012; McLean, 2009). They have included criteria for assessing the quality of course plans, teacher practice, and student achievement. The procedures for selecting high-performance schools have usually focused on indicators of performance, rewarding those found to 
be excellent (King \& Mathers, 1997). Procedures for officially rewarding and recognising teachers have commonly involved teachers' courses being initially evaluated by their leaders and peers, with those courses recognised as excellent being nominated to participate in official course competitions for further evaluation and reward (Huggett et al., 2012). Competitions for evaluating and recognising student achievements in vocational education have commonly involved students competing in national skills competitions, with the education providers of successful students being rewarded (Hillier, 2009).

Vocational education that is preparatory for vocational occupations has commonly been divided to two educational levels: secondary and postsecondary vocational education (OECD, 2009). Post-secondary vocational education is known as higher vocational education (HVE) in certain countries, including China, The Netherlands and Sweden (Bathmaker, 2017; Littke \& Thång, 2015). Higher vocational education includes diploma-based and degree-based education (OECD, 2014), both aiming to build higher skills in students than those targeted in secondary vocational education.

The Chinese Ministry of Education (MOE) (2016) has stated that higher vocational education in China focuses on fostering highly skilled manpower and is an important part of higher education provision, its enrolment accounting for half the total enrolment in higher education (MOE, 2016). HVE is mainly provided by HVE institutes which offer diploma-based programs (Guo \& Lamb, 2010). Public institutes are the major HVE providers (MOE, 2007), and both public and private institutions are regulated by central and local governments (MOE, 1996). The organisational structure in HVE colleges is similar, because it is regulated by the Chinese Ministry of Education (2000). The top management in a college comprises the Chairman and Principal with several vice-principals. A college includes several departments responding to different industry sectors. Each department contains several disciplines, each of which is a particular area of study preparing students for a particular work field or occupation. For example, electronics is a discipline that aims at fostering future electronic technicians. The heads of the departments are deans - middle management - and there are academic deans who take charge of teaching matters. Under the deans are the discipline heads who are persons who take charge of curriculum development and who work with a number of teachers in their discipline. They are responsible for the curriculum plans, which contain objectives, duration, and a set of courses to be offered in the discipline, each of which contains the delivery of part of the knowledge and skills in its curriculum.

With the economic and technological developments over recent decades in China, skilled manpower has been in high demand by industry. In response to this situation, the Chinese State Council (2005) and the MOE (2006) have advocated employment-responsive HVE curriculum reform. The resulting policy reform emphasizes the importance of HVE curriculum being work-related, responsive to enterprise needs, and practical. The government has used a rewards and recognition scheme to motivate colleges' and teachers' adoption of the curriculum reform since it was enacted.

In recent years, there have emerged points of criticism of the effectiveness of such schemes in promoting improvements in education practice and curriculum reform in China and other countries. Although many schools and teachers have been found to be motivated by rewards and recognition, some teachers have not seen them as being attractive (Kelley, 1999). Funding schools on the basis of their performance has been argued to exacerbate inequalities between schools in the USA (King \& Mathers, 1997).

In China, HVE colleges and their departments tended to support curriculum selected to enhance their preparation for the competitions, at the expense of alternative curriculum, which they have considered to be less advantageous (Zhao, 2011). The evaluation criteria used in the competitions have also been found to be regarded as unreliable in evaluating educational practice and performance (Harvey-Beavis, 2003). For example, although the curricula in many colleges have been rated by the government as excellent examples of reform implementation, some of them have been questioned by teachers as not meeting or realising the reform requirements (Tong \& Jiang, 2016).

The research reported in this paper examined the influences of the rewards and recognition scheme on curriculum reform from the perceptions and experience of discipline heads who were responsible for curriculum reform in their disciplines. That report begins in the next section by presenting a more focused overview of the rewards and recognition scheme in the context of the HVE curriculum reform in 2006. This is followed by an outline of the research project from which the data used in the study here reported were drawn. The pertinent findings from that research project are then presented and discussed. The conclusions drawn from the study are then presented, with their implications for future research and practice.

\section{The Research Background}

With the economic and technological developments over recent decades in China, skilled manpower has been in 
significant demand in labour markets. In response to this situation, the MOE (2006) enacted employment-responsive HVE curriculum reform in 2006. The reform aimed to improve the performance of HVE colleges in developing highly skilled manpower for labour markets through re-developing their curricula to make them more responsive to the needs and requirements of industry. The key content of the curriculum policy reform was clearly defined:

One important feature of HVE is adjusting and setting disciplines based on the needs of local economic development. ... Curriculum development and reform is the core of improving HVE education quality, and it is also the key challenge. HVE institutes should actively cooperate with sectors and enterprises to develop curricula. The curriculum development should be based on job requirements for expertise in fields and occupational positions. ... In order to promote the integration of work, social practice and education in colleges, work-integrated learning is an important educational model in HVE. ... The education aim is to foster high calibre and skilled manpower. (MOE, 2006)

This curriculum reform policy has been introduced into HVE in China over the last 10 years. A significant approach to encouraging its adoption has been to develop what is here termed 'a rewards and recognition scheme' in which the state recognises and rewards selected curriculum as examples of 'excellent' implementation of the reform. The scheme is based on the idea that offering rewards and recognition will encourage colleges and teachers to better implement the curriculum reform. Exemplifying and showcasing such successful adoption of the reform in HVE college curricula will then encourage other providers to follow those examples (MOE, 2006). Official student skill competitions have also been held to assess and recognise students' practical skills. The competitions have been aimed at encouraging colleges and teachers to improve the cultivation of student skills highlighted in the curriculum reform. Both the curriculum and the skill competitions amount to an official rewards and recognition scheme where teachers can win financial support for their further curriculum development and official recognition of the quality of their curriculum reform.

Curriculum competitions were initiated by the central government in 2003, before the curriculum reform was enacted in 2006, and developed to recognise and reward selected curricula of good quality. At the beginning, the curriculum competition held by the MOE was named 'Excellent Course'. In the competition, some courses in a college were first selected by the management, and then compared with the selected courses from other colleges in terms of quality at the national level (MOE, 2003). The criteria of quality were general, and included teachers' experience, updated knowledge, appropriate teaching methods, and emphasis on practical teaching. The courses rated by the national evaluation as excellent were further financially supported. The competition aimed at motivating educators to improve course quality and to share their excellent courses (MOE, 2004).

The curriculum competitions have continued and have begun to emphasise the evaluation of curriculum reform since the reform was enacted in 2006. The MOE (2006) saw the competitions as providing an incentive for local governments and colleges to implement the curriculum reform, and as encouraging others through showcasing 'Excellent' curriculum online for them to draw upon. In 2007, the MOE relaunched the "Excellent Course" competition using evaluation criteria based on the curriculum reform policy. At the same time, the course competitions began to be broadened to encompass competitions of whole curricula in a discipline. The government also decided to select and financially support 500 curricula that were fully reformed and well developed to service local industry (MOE, 2006) The government nominated and advocated some emerging industries, which became the targets of the curriculum competition activities (MOE, 2007). In recent years, many curriculum competitions have been held by the MOE, although they are variously named, such as "Excellent Course" and "HVE Discipline Teaching Database". While the evaluation criteria to assess the quality of curricula in these curriculum competitions have been essentially the same, and still based on the initial HVE curriculum reform policy, the more recent competitions have put more emphasis on online sharing of the curricula rated as excellent.

The first session of student skill competitions mainly referring to some engineering disciplines was held by the MOE in 2008. In those competitions, students were chosen and recommended by their colleges on the basis of their performance of practical skills emphasised in the policy (MOE, 2008). Participating students were assessed on their performance of the skills through evaluating their completion of projects designed by the MOE (2008). The winning students and their colleges were rewarded in order to motivate more colleges to focus on fostering students' learning of the skills highlighted in the curriculum reform. In the following years, the competitions were extended to include more HVE disciplinary fields, such as business and animation (Lu \& Zhang, 2011).

In response to those curriculum and skill competitions developed by the central government, local governments also launched curriculum and skill competitions to promote curriculum reform (Lu \& Zhang, 2011; Wang, 2010). 
For example, the Education Department in Jiangsu held 'Excellent Course' competitions, 'Key Developed Curriculum' competitions and student skill competitions at the provincial level in order to promote curriculum implementation in the province (JPED, 2008, 2012). Curriculum rated by provincial departments as excellent could then be recommended for inclusion in national competitions (MOE, 2006). Colleges also held curriculum competitions, where curricula rated by colleges as excellent would be recommended to the curriculum competitions of central and local governments (Lu \& Zhang, 2011).

\section{The Research Project}

The research reported here was part of a doctoral research project undertaken by the lead author, exploring discipline heads' experience of curriculum reform in HVE in China. The research was aimed at obtaining an insight into discipline heads' understanding of the curriculum reform policy and their experience of implementing it, including the factors they saw as influencing their implementation, and their recommendations for ways in which these efforts might better have been supported. The present paper focuses, though, just on their perceptions and experience of the influence of the rewards and recognition scheme on their reform efforts. This section explains the key features of the research project: the key concepts as they were used in conceptualising the project, the research methodology, matters of research integrity and ethical issues raised by the research.

\subsection{Key Concepts}

The concept of curriculum used in the study was that of what should be taught (Ross, 1999). Thus, curriculum was conceptualized "as text, ministry document, and resources that teachers are responsible for implementing" (Ross, 1999, p. 8): what should be taught, how it should be taught, and the intended learning outcomes (Johnson, 1967). Accordingly, a curriculum design or reform was seen as concerning what subject matter should be included in a curriculum, and what delivery methods of subject matter should be adopted (Ross, 1999).

The research, though, sought specifically to respond to a need, identified by Tilley and Taylor (2013), for research focusing on teachers' experiences concerning curriculum: teachers' understanding, thoughts, and actions about curriculum design and curriculum reform. In other words, it sought to focus on the need for research to explore the subjective meaning of curriculum and curriculum reform articulated from the lived experience of teachers. From that subjective viewpoint of those responsible for implementing the curriculum reform policy, curriculum and its reform are closely interwoven when teachers reflect on, make decisions on, and take actions to design curriculum plans (Cho, 2001), suggesting the notion of 'curriculum-as-plan' - developed by Aoki (1993) - conceptualizing teachers' experience of reforming curriculum. Based on their own knowledge and experience and their understanding of the curriculum policy, teachers consciously form and implement plans for what they and their students should do in the classroom. This concept of curriculum-as-plan, then, focuses on teachers' subjective interpretations of changes to curriculum policy and their experiences of responding to those interpretations in the context of their prior experience and their understanding of how environmental factors may impact on their curriculum reform efforts.

A rewards and recognition scheme was seen in the research project as an incentive system, as explained above. King and Mathers (1997) had noted that schemes aimed at having incentive effects could be explored through studying teachers' perceptions of the schemes. The rewards and recognition scheme was thus seen as a factor influencing the participants' curriculum reform efforts. The participants' experiences of that influence could thus be investigated through interviews with them to elucidate their interpretations of those experiences.

\subsection{Methodology}

This research project was phenomenological in nature (Van Manen, 2014). Phenomenology is seen as a rigorous approach to exposing the essence of people's lived experience (Husserl, 2012). This approach fits the research aim, namely exploring discipline heads' experience and perceptions of the influence of the rewards and recognition scheme on HVE curriculum reform in China. Further, people's narratives are seen as the best way to express their individual and social lived experience, and interviews are normally used as the method to explore and gather narratives (Van Manen, 2014). Through in-depth interviews, the description of lived experience can be very concrete, involving a specific instance, situation, person, time period, or event.

This research reported here drew on semi-structured, in-depth interviews with 15 HVE discipline heads from two public HVE colleges in a city of Yangtze River delta. A purposeful selection approach was used, and sites were selected that could best inform the study (Yin, 2009). The selected city was seen as being at the leading edge of socio-economic development in China, with highly developed manufacturing and commercial sectors. In order to meet local demand for skilled local labour, and also reflecting their higher revenue relative to other regions, the 
provincial and city governments have provided more financial support to the HVE colleges in the selected city than has been available to HVE colleges in most other cities in China (MOE, 2012). This selection therefore served as a strong example of what may be experienced in the development of the policy initiative being studied. It was thus assumed that the discipline heads in the colleges would have implemented curriculum reform more completely and developed a richer experience of curriculum reform and its influencing factors. The lead author had also previously worked at an HVE college in the city, so was familiar with local colleges and situations, allowing him to select colleges and discipline heads that would best inform the research.

Pietkiewicz and Smith (2014) argued that researchers could select approximately a dozen cases for obtaining rich data from in-depth interviews in phenomenological research. Accordingly, 15 discipline heads were selected from two colleges in the selected city: eight from one college, and seven from the other. In both colleges, the selection of different vocational education disciplines embraced a diversity of different discipline content, since discipline heads' experience was seen as potentially varying across discipline contexts. Similar disciplines were selected in both colleges: accounting, business, mechanical engineering, electronic engineering, information technology, and animation.

The lead author selected the first public college as a comprehensive and progressive HVE provider, and was referred to the second by the Chairman of the first college. The selection of discipline heads in the two colleges was conducted by the academic deans, based on a set of selection criteria provided by the lead author to ensure appropriate depth of experience in implementing the curriculum reform and to ensure disciplinary diversity in both colleges and comparability across the two colleges. The academic deans gave the lead author a list showing the contact details of the discipline heads who agreed to participate in this research.

Fourteen of the 15 participants each participated in two audio-recorded interviews, the two for each participant lasting for a total of between two and three hours, while one participant was interviewed just once for two hours. Both interviews explored the participants' relevant lived experience, while the second was also used to clarify and expand on any points arising from the initial analysis of the first interview. Every interview recording was transcribed verbatim by the lead author as soon as the interviews were completed. Data analysis followed the procedures of phenomenological thematic analysis (Van Manen, 1984), through which themes were derived from discipline heads' descriptions and reflections of their understanding and lived experience of implementing the curriculum reform. This paper, though, focuses just on the themes concerning the rewards and recognition scheme.

To protect the anonymity of the participants, each was given a pseudonym, which has been used to identify any narrative extracts and vignettes used here in grounding the emergent themes. The participants' pseudonyms used here are: Cong, Dui, Fang, Gong, Heng, Hui, Ruo, Sei, Sun, Wen, Xiao, Xing, Yan, Zhong, Zhuo. Gong, Ruo, Sun and Xing are female, while the others are male.

\subsection{Research Integrity}

To enhance the trustworthiness and believability of the findings (Lincoln \& Guba, 1985), several strategies were adopted. First, the most appropriate research approach and research method were adopted to investigate participants' perceptions: interpretative phenomenology (Van Manen, 1990). Second, the two sites (the colleges) were chosen by the lead author is those most appropriate for the study. The selection thus reflected the lead author's understanding of the local contexts and facilitated his building understanding and trust with the participants, in order to obtain authentic narratives. Third, through using narrative extracts and vignettes from the participants, readers may better comprehend the emergent themes identified by the researcher. Fourth, the findings are grounded in the voices of the different participants, each finding here normally being illustrated by two or more representative narrative extracts or vignettes. Fifth, the contexts of the participants' experiences presented here allow readers to make decisions regarding transferability of the findings to other situations (Creswell, 2013). Finally, to support the dependability (the stability) of the findings, the design, data collection, and data analysis procedures are presented here explicitly and in detail for future researchers to assess (Shenton, 2004).

\subsection{Ethical Issues}

The core principle in addressing ethical issues in human research may be seen as "respect for human beings" (National Health and Medical Research Council, Australian Research Council, \& Australian Vice-Chancellors' Committee (NHMRC, ARC, \& AVCC, 2013, p. 9). In that regard, potential participants made their own decision to participate in the research (Creswell, 2012). They were contacted before the interviews took place, in order to further check the voluntary nature of their participation. The consent forms identified their voluntary participation and their option to withdraw at any stage of the research without penalty, while also disclosing 
sufficient information about the research project and their contribution to it.

An ethical priority in research is also to protect participants from potential harm or discomfort (Lawrence, 2007). In the consent forms and before each interview, participants were assured that their anonymity would be maintained throughout the research and its publication. All the data were anonymised: all direct identifiers, such as names and addresses, being changed (Olesen, 2014). Each participant was assigned a pseudonym. The names of their disciplines were changed to general terms, usually the names of the industries to which they belonged, for example, 'electronics industry' instead of 'semiconductor manufacturing' (the discipline). The names of the selected colleges and the city were removed, and the original name of the province was changed to the name of the region. The information regarding the selected city in terms of its economic and social characteristics has been withheld, and there are several similar cities in that region, so the selected city could not be identified. Thus, third parties cannot link the de-identified data to individuals and the selected colleges.

\section{Findings}

The analysis of participants' narratives revealed their perceptions of the influence of the rewards and recognition system on their curriculum reform efforts. These perceptions have been aggregated through the analysis into emergent themes. Each of the four emergent themes is here given a brief descriptive label, under which it is first explained, then descriptively elaborated and grounded in the interview data using translated narrative extracts and selected vignettes, as appropriate.

The first theme identifies the participants' positive perceptions of the rewards and recognition scheme. The other three themes identify the drawbacks of the scheme: funding inequality, misleading guidelines, and inappropriate evaluation.

\subsection{Positive Perceptions}

Only eight participants, just over half the total of 15 participants, saw the rewards and recognition system as providing external incentives that motivated their participation in seeking to implement the reform. They reported that they reformed some courses because they wanted to win rewards for funding their continuing curriculum reform and to win recognition, which would facilitate their promotion. For example, Cong explained the reason why he wanted to participate in a national curriculum competition as:

I could not refuse it. Why? I knew there was plenty of money.

Zhuo reaffirmed that view:

You will not obtain official funding, if you do not win in a curriculum competition.

Zhong also noted that teachers, including himself, were motivated by the potential rewards and recognition, which could contribute to title promotion in HVE colleges:

Let me tell you a secret. ... All teachers fight for title promotion [from Lecturer to Professor]. If you had no achievement in curriculum reform, your college would not upgrade your title.

The rewards and recognition scheme, though, was not regarded by Fang and Ruo as attractive. They said their reforms were undertaken because they recognised them as good for improving their education practice:

I reformed my course because I recognised the [value of the] reform, rather than to win rewards. (Fang)

I have never been interested in winning rewards. I just want to pursue a good curriculum reform implementation and to improve my educational practice. (Ruo)

Monetary rewards from curriculum competitions were seen by just four participants as supporting winners' curriculum reform and development:

Through winning the college-based course competition, I was rewarded with a small amount of funding. I used the funds to purchase some stuff, such as equipment components and teaching aids used in classes. (Sun)

There were many governmental curriculum competitions. To be honest, besides regulatory financial funds [to cover discipline expenses], most of the other funds for curriculum reform were from those competitions. ... Only after our course was rated as an Excellent Course in our province, was an amount of funding given to us and used for our further curriculum development. ... In fact, the further development of our curriculum depended on the funds. (Zhong)

Cong recalled that, with funds from a national competition, he had invited some experienced educators to assist him in further curriculum reform. 


\subsection{Funding Inequality}

The reform of many curricula was regarded by Fang, Sei, Sun, and Xing as not benefiting from the funding through the rewards and recognition system, because only a small number of curricula could be rated as excellent and rewarded in each competition:

It was the first time that I participated in Excellent Course Competitions in the city, ... and only three courses were recommended by my college. ... One was mine. ... The teachers of the other two courses were rewarded. My course was not chosen. (Fang)

My college recommended two disciplines in a provincial curriculum competition. ... It was very competitive. ... My curriculum was not good enough. (Xing)

In a national level curriculum competition, our college was only allowed by the central government to recommend two curricula. (Sei)

Five participants noted that the curriculum reform of discipline heads and teachers who were seen by their colleges as having more opportunity to win curriculum and skill competitions was regarded as being more likely to be supported by their colleges in preparation for the competitions:

For letting me participate in a relevant national skills competition, the college had to buy it. ... The college supported me to participate... because I had won several prizes in curricula and skills competitions before. ... The practice of the equipment with the new technique was introduced into my curriculum. (Sei)

Xiao reported that the college management thought his discipline was likely to be rewarded. In order to increase his competitiveness, the college invested a large amount of funding in building a college-based workshop as the training room. Practice in those rooms enhanced students' practical skills. Dui commented that, in the Chinese education system, a discipline head was expected to obtain rewards and recognition for their college, which brought recognition to his curriculum and his college. Any discipline head who had the capability to win rewards, was seen as likely to get support from the college to further their curriculum reform.

Correspondingly, three participants who saw themselves as being regarded by their colleges as having less opportunity to win, reported having little college support for their curriculum reform:

Compared with disciplines that usually won rewards, the Dean paid less attention on my discipline and I had much less funding. (Sun)

Dui said that, at the beginning of his curriculum reform, he did not have dedicated training rooms for his students, but that:

After my students won all the prizes in a skills competition in the city, my college began to recognise me, and provided me a training room, which was previously not offered to me.

Zhong recalled that, before he and his teachers won a curriculum competition, his discipline was undervalued by his Dean and under supported.

Dui, Sun, Yan and Zhong reported that only a small number of curriculum reform initiatives were recognised by the government and rewarded through the system, and colleges tended to support discipline heads whose curricula were regarded more likely to win. In that case, the reform of other curricula that were not recognised by the government and the colleges as excellent were seen as being constrained with comparatively less support:

Through lack of support, the quality of my curriculum suffered, because of a lack of equipment. (Sun)

The value of all the equipment in my discipline was 3 million Yuan. ... I heard that the same discipline in another college won 20 million Yuan from the central government. We certainly are not its competitors. (Yan)

Zhong noted that the rewards from the government and relevant support from colleges all focused on supporting excellent curricula, which could then be further developed. On the other hand, less developed curricula had fewer opportunities to be supported, so it was difficult for them to make progress. The gap between the quality of excellent curricula and less developed thus curricula became larger.

\subsection{Misleading Guidelines}

The foremost requirement in curriculum the reform has been to develop curriculum based on industry needs. To promote the implementation of this requirement, the Government identified and advocated some emerging industries, with curricula relevant to those industries being more likely to be recognised in official curriculum competitions (MOE, 2007). Among the participants, two discipline heads in one selected college reported that 
they had experience of taking charge of establishing new disciplines in response to the government's guidance on the industry.

However, curriculum reform was recognised by Xiao as being limited by misleading guidance on the target industries in the scheme. As a result, new industry was not being supported. Following the Government's guidelines was regarded as resulting in curriculum development that failed to meet labour market needs. As a consequence, many graduates were reported to be underemployed:

My discipline was developed for an industry that was regarded as emerging by the country, ... but at that time the industry had declined. ... Few graduates could expect to be employed by the enterprises in that sector. (Xiao)

In response to the Government's identification of an emerging industry, many colleges also developed relevant disciplines at the same time, resulting in an over-supply of graduates:

The Government said that animation was an emerging industry and advocated the development of relevant disciplines. ... As a result, according to my investigation, nearly all colleges in this area, including mine, developed this discipline. Just imagine how the labour market could accommodate all the future graduates. Not unexpectedly, many graduates could not find relevant jobs. (Dui)

\subsection{Inappropriate Evaluation}

Through evaluating curricula, the scheme seeks to reward those colleges and teachers developing curricula judged to be excellent, posting those curricula as showcases. However, the curriculum competitions were regarded in this study as likely to select courses with poor quality curriculum - rejecting curriculum appropriate to the reform - due to inappropriate evaluation criteria and processes. The scheme's aims of selecting excellent curriculum to reward and to post online for other teachers to draw on were thus regarded as being compromised. The inappropriateness of the assessment criteria to evaluate curriculum reform and the lack of assessment skills on the part of the assessors were seen as being the main problems:

There is a criterial framework in curriculum competitions, including the teacher's title. ... However, there are no criteria to directly assess the quality of a curriculum itself; none that assess whether a curriculum development was based on relevant industry standards. (Ruo)

I participated in many curriculum competition activities, but there were never assessors with relevant industry experience to evaluate my curricula, and they did not understand my course. ... In a course competition among three courses, ... my course was regarded by the other teachers as the best one, because I had completely reformed my course based on the policy. ... However, I did not win because of my title was regarded by experts as low in the competition, ... while a course without full policy implementation was selected. (Fang)

Yan recalled that, when he participated in his dean's course reform, although the dean's course design deviated from the policy requirement, his textbook based on the course design was still rated by the evaluators of the provincial government as excellent and was published:

At the beginning of the course development, he [the dean] said he would design a project-based course [as the policy required], and he designed ten projects. ... To be honest, those projects should not have been seen as projects and I did not recognise them as such. ... Unexpectedly, his textbook was rated by the local government as excellent. So, I really doubted the capability of so-called experts [the evaluators].

Correspondingly, only two participants saw the quality of the curriculum rewarded and posted online as being of such a standard that it would be useful as a basis for their own curriculum design:

I browsed some courses rated as excellent online.... I could draw on some course content. (Sun)

I browsed the plans of some excellent curriculum. I drew on some ideas of how to design my course. (Zhong)

\section{Discussion}

The findings of this study revealed how the rewards and recognition scheme, as an institutional factor, influenced HVE curriculum reform in two public colleges in China. Some of the participants spoke of their being motivated by the scheme to engage in curriculum reform and saw their curriculum reform as being supported by funds provided through the scheme and from their colleges in preparation for the competitions in the system. On the other hand, the effectiveness of the scheme was seen by participants as being limited in its impact because of funding inequity, misleading guidelines, and ineffective evaluation. 
Just over half the participants saw the rewards and recognition scheme as motivating them to engage in curriculum reform. Potential rewards, in form of funds, were regarded as an economic incentive. The public recognition of their reform work was seen as facilitating their promotion and as motivating them to commit to fully implementing the reform. This finding was similar to Kelley's (1999) finding - from a survey of teachers in four states in the USA - that performance-based bonuses, performance-based funding for school improvement, and public recognition for teaching and learning achievements were regarded by most of them as incentives for them to improve and reform their educational practice. As in the present study, Kelly also found that only a small portion of the teachers saw the rewards and recognition as unattractive. Similarly, King and Mathers (1997) through interviews with 16 policy actors including local education officers at the state level, school administers and teachers in schools in four states of the USA - found that rewards and recognition as extrinsic incentives were regarded as having less incentive effect than intrinsic motivation in improving educational practice.

The present study's finding that the rewards and recognition system resulted in the unequal allocation of educational resources, confirms the finding of Zhao (2011) in his survey of 45 teachers and 200 students in a secondary school in China. He found that a curriculum selected by the school to participate in skill competitions was provided with much more funding and facilities, compared with other curricula. King and Mathers (1997) through interviews with 16 policy implementers, including local education officers at the state level, school administers and teachers in schools in four states of the USA - concluded that funding schools based on their performance might lead to inequality of allocation of education sources: while some high-performance schools would benefit from the scheme, the education problems in other low-performance schools might be exacerbated. They suggested that performance-based funds should account for only a small portion of the total funds, and funding should be mainly based on educational considerations.

A finding in this study, misleading guidelines, is a significant contribution to the literature in that it. This position is supported by Billett's (2004) suggestion that enterprises and sectors should be involved in decision-making in vocational education to elaborate the training needs of the industry. The deformation of the HVE system created by such misleading guidelines may lead to the oversupply of new curriculum and a surfeit of graduates.

Also significant is the finding that the evaluation in curriculum competitions was regarded by many participants as ineffective, because of a lack of appropriate evaluation criteria to assess the reform implementation and evaluators' lack of evaluation skill. However, it aligns with Van den Berghe's (1997) finding - from his discussions with vocational education experts mainly from six European countries - that evaluation in vocational education is commonly regarded as unreliable because of the failure of the evaluation criteria. Further, Harris-Huemmert's (2008) study of 18 evaluators of the performance of higher education institutions in Germany is also relevant in it suggesting that a capable evaluator must master knowledge of relevant disciplines. There remains, then, the challenge of designing appropriate, effective and comprehensive evaluation criteria for assessing vocational education reform. In that regard, McLean (2009) suggested that vocational education evaluators should master knowledge of curriculum reform and relevant expertise and that other stakeholders, including students and peers, should be involved, in order to evaluate programs more comprehensively.

\section{Conclusions and Recommendations}

From the findings of this study, it may be concluded that, in the two colleges studied, the rewards and recognition scheme has limited support among those key players who are responsible for its implementation in HVE: the discipline heads within the colleges. Half of those discipline heads surveyed across a diversity of disciplines saw the scheme as an incentive for them or their teachers to engage in the curriculum reform mandated by the Central Government. They saw it as a flawed system, especially with regard to:

(1) Its contribution to funding inequalities across disciplines and providers.

(2) Its inadequacy in providing a coherent response to its primary purpose: that of ensuring the provision of HVE more appropriate to the needs of industry and emerging industries.

(3) Its unsubstantiated and untested criteria and procedures that could intelligently be reliably expected to produce the curriculum reform outcomes expected of it.

While the generalisability of these conclusions to other colleges across China remains an open question at this stage, the following recommendations are offered here for reforming the rewards and recognition scheme in China:

That the Chinese Central Government's rewards and recognition scheme in higher vocational education be reviewed and revised to address their limitations identified, particularly to ensure that:

(1) The scheme does not contribute to funding inequalities across colleges or disciplines. 
(2) The guidelines on the workplace and emerging industry needs should be updated in order to optimally serve its primary purpose of facilitating the development of HVE provision that is responsive to the needs for higher vocational skills.

(3) The criteria and procedures used to assess any curriculum nominated for reward and recognition under the scheme are optimal to meeting the expectations of the scheme.

The findings and conclusions drawn from the study may also be seen as a cautionary case study. They inform other vocational education jurisdictions on issues that may arise, and to which they should be particularly alert, in their design and implementation of similar such schemes. The scheme might be an important but not the only official way to foster teachers' commitment to curriculum reform, because not all the teachers may be attracted by the external incentives. The scheme should be not an important way of funding, and funding should be mainly based on educational needs. The scheme should build a close link to industry and HVE colleges, and invite people with the good knowledge of industry and vocational education, to make updated guidelines on industry needs and effectively evaluate the status of completion of curriculum reform in competitions.

It is suggested that the nature of the findings and conclusions drawn from this study suggest the urgency of undertaking more comprehensive studies of the implementation of the rewards and recognition scheme in China, to develop a more firmly grounded understanding of the nature and extent of the issues identified and of the most appropriate responses to them. In addition, it is recommended for further study to explore how to design appropriate, effective and comprehensive evaluation criteria for assessing vocational education reform.

\section{References}

Amabile, T. M., Hill, K. G., Hennessey, B. A., \& Tighe, E. M. (1994). The work preference inventory: Assessing intrinsic and extrinsic motivational orientations. Journal of Personality and Social Psychology, 66(5), 950-967. https://doi.org/10.1037/0022-3514.66.5.950

Aoki, T. T. (1993). Legitimating lived curriculum: Towards a curricular landscape of multiplicity. Journal of Curriculum and Supervision, 8(3), 255-268.

Bathmaker, A.-M. (2017). Post-secondary education and training, new vocational and hybrid pathways and questions of equity, inequality and social mobility: Introduction to the special issue. Journal of Vocational Education \& Training, 69(1), 1-9. https://doi.org/10.1080/13636820.2017.1304680

Billett, S. (2004). From your business to our business: industry and vocational education in Australia. Oxford Review of Education, 30(1), 13-35. https://doi.org/10.1080/0305498042000190041

Chinese State Council. (2005). Guowuyuan guanyu dali fazhan zhiyejiaoyu de jueding [The State Council's descisions on vigorously developing vocational education]. Retrieved from http://www.gov.cn/zwgk/2005-11/09/content_94296.htm

Cho, J. (2001). Curriculum implementation as lived teacher experience: Two cases of teachers (Doctoral dissertation). $\quad$ Retrieved

from https://etd.ohiolink.edu/!etd.send_file?accession=osu1488204276531133\&disposition=inline

Creswell, J. W. (2012). Educational Research: Planning, Conducting, and Evaluating Quantitative and Qualitative Research (4th ed.). Boston, USA: Pearson Education.

Creswell, J. W. (2013). Qualitative inquiry and research design: Choosing among five approaches (3rd ed.). New York: Sage Publications.

Gayles, J. (2007). Race, reward, and reform: An implicative examination of the florida school recognition program. Educational Policy, 21(3), 439-456. https://doi.org/10.1177/0895904806289216

Gretton, S., \& Raine, D. (2015). Reward and recognition for university teaching in STEM subjects. Journal of Further and Higher Education, 41(3), 301-313. https://doi.org/10.1080/0309877x.2015.1100714

Guo, Z. Y., \& Lamb, S. (2010). International comparisons of china's technical and vocational education and training system. Dordrecht, Netherlands: Springer. https://doi.org/10.1007/978-90-481-8743-0

Hanson, J. (2003). Encouraging lecturers to engage with new technologies in learning and teaching in a vocational university: The role of recognition and reward. Higher Education Management and Policy, 15(3), 135-149. https://doi.org/10.1787/hemp-v15-art28-en

Harris-Huemmert, S. (2008). Evaluators of higher education in Germany: Are they 'fit for purpose'? Quality in Higher Education, 14(1), 55-65. https://doi.org/10.1080/13538320802011722 
Harvey-Beavis, O. (2003). Performance-based rewards for teachers: A literature review. Retrieved from http://www.oecd.org/edu/school/34077553.pdf

Hillier, Y. (2009). Innovation in teaching and learning in vocational education and training: international perspectives.

Retrieved

from https://www.ncver.edu.au/publications/publications/all-publications/innovation-in-teaching-and-learning-invocational-education-and-training-international-perspectives-research-overview

Huggett, K. N., Greenberg, R. B., Rao, D., Richards, B., Chauvin, S. W., Fulton, T. B., . . Simpson, D. (2012). The design and utility of institutional teaching awards: A literature review. Medical Teacher, 34(11), 907-919. https://doi.org/10.3109/0142159X.2012.731102

Husserl, E. (2012). Ideas: General introduction to pure phenomenology. New York: Routledge.

Johnson, M. (1967). Definitions and models in curriculum theory. Educational Theory, 17(2), 127-140. https://doi.org/10.1111/j.1741-5446.1967.tb00295.x

JPED. (2008). Shengjiaoyuting guanyu kaizhan 2008nian jiangsusheng gaodengxuexiao jingpinkecheng jianshegongzuo de tongzhi [Prinvicial education department's notice on implementing Jiangsu province's higher vocational education couse competitions in 2008]. Retrieved from http://www.ec.js.edu.cn/art/2008/3/7/art_4627_24808.html

JPED. (2012). Shengjiaoyuting guangyu juban 2012nian jiangsusheng gaodengzhiyeyuanxiao zhinengdasai de tongzhi[Provincial education department's notice on holding Jiangsu higher vocational education college skill competition]. Retrieved from http://www.ec.js.edu.cn/art/2012/2/24/art_4267_65589.html

Kelley, C. (1999). The motivational impact of school-based performance awards. Journal of Personnel Evaluation in Education, 12(4), 309-326. https://doi.org/10.1023/a:1008011810852

Kelley, C., \& Protsik, J. (1997). Risk and reward: Perspectives on the implementation of Kentucky's school-based performance award program. Educational Administration Quarterly, 33(4), 474-505. https://doi.org/10.1177/0013161x97033004004

King, R. A., \& Mathers, J. K. (1997). Improving schools through performance-based accountability and financial rewards. Journal of Education Finance, 23(2), 147-176.

Ladd, H. (2011). Holding schools accountable: Performance-based reform in education. Washington, D.C.: Brookings Institution Press.

Lawrence, D. J. (2007). The ethics of educational research. J Manipulative Physiol Ther, 30(4), 326-330. https://doi.org/10.1016/j.jmpt.2007.03.005

Lincoln, Y. S., \& Guba, E. G. (1985). Naturalistic inquiry. Beverly Hills, CA: Sage Publications.

Littke, K., \& Thång, P.-O. (2015). Learning at work in higher vocational education. Nordic Journal of Vocational Education and Training, 5(1), 1-17. https://doi.org/10.3384/njvet.2242-458X.15v5i1a3

Lu, S., \& Zhang, Q. (2011). Peiyang zhiyenengli: Dui zhiyeyuanxiao jinengdasai de lixing sikao [How to cultivate occupational competence: Rational thought on the skills competition of the national vocational institutions]. Zhiyetongxun [Vocational Education Communication], (5), 14-17.

McLean, M. (2009). Rewarding teaching excellence. Can we measure teaching 'excellence'? Who should be the judge? Medical Teacher, 23(1), 6-11. https://doi.org/10.1080/01421590123039

MOE. (1996). Zhonghuarenmingongheguo zhiye jiaoyufa [Vocational education law of the People's Republic of China]. $\quad$ Retrieved from http://old.moe.gov.cn/publicfiles/business/htmlfiles/moe/moe_2803/200907/49983.html

MOE. (2000). Jiaoyubu guanyu jiaqian gaozhigaozhuan jiaoyu rencai peiyang gongzuo deyijian [MOE's suggestions on enhancing higher vocational education]. Retrieved from http://old.moe.gov.cn//publicfiles/business/htmlfiles/moe/s7056/201401/xxgk_162628.html

MOE. (2003). Jiaoyubu guanyu qidong gaodengxuexiao jiaoxuezhiliang yu jiaoxuegaige gongcheng jingpinkecheng jianshe gongzuo de tongzhi [MOE's notice on launching the development of teaching quality and teaching reform in Higher education institutes]. Retrieved from http://old.moe.gov.cn//publicfiles/business/htmlfiles/moe/s3843/201010/109658.html

MOE. (2004). Jiaoyubu bangongting guanyu 2004niandu guojia jingpinkecheng shenbao gongzuo de tongzhi[The notice of office of MOE on application for participation in the national excellent course 
competition in 2004]. $\quad$ Retrieved from http://www.moe.gov.cn/s78/A08/gjs_left/s5664/moe_1623/s3843/201010/t20101018_109654.html

MOE. (2006). Jiaoyubu guanyu quanmiantigao gaodengzhiyejiao yu jiaoxuezhiliang de ruoganyijian [Some suggestions on improving the overall quality of higher vocational education]. Retrieved from http://old.moe.gov.cn//publicfiles/business/htmlfiles/moe/moe_1464/200704/21822.html

MOE. (2007). Number of regular higher educational institutions. Retrieved from http://www.moe.edu.cn/publicfiles/business/htmlfiles/moe/moe_1661/200710/27228.html

MOE. (2008). Jinengjingsai jiaoyubu guanyu juban 2008nian quanguo zhiye yuanxiao jinengjingsai de tongzhi [MOE's notice on holding the national skill competition of vocational colleges and schools in 2008$].$ Retrieved from http://www.moe.gov.cn/srcsite/A07/zcs_yxds/s3069/200802/t20080228_79000.html

MOE. (2012). Jiangsu cujin gaodengzhiyejiaoyu fazhan zonghe gaige shidian diaoyan baogao[Jiangsu promoting higher vocational education development: Investigative report of comprehensive reform pilot]. Retrieved from http://www.moe.edu.cn/publicfiles/business/htmlfiles/moe/s6634/201207/139559.html

MOE. (2016). Transforming vocational education. Retrieved from http://en.moe.gov.cn/Specials/Specials_Spotlight/Spotlight_Opinions/201603/t20160309_232689.html

National Health and Medical Research Council, Australian Research Council, \& Australian Vice-Chancellors' Committee. (2013). National Statement on Ethical Conduct in Human Research 2007. Retrieved from https://www.nhmrc.gov.au/guidelines-publications/e72

OECD. (2009). Working out change: Systemic innovation in vocational education and training. Retrieved from http://www.oecd-ilibrary.org/education/working-out-change_9789264075924-en;jsessionid=14twgcrio4xid. delta

OECD. (2014). Skills beyond school: OECD reviews of vocational education and training. Retrieved from $\mathrm{http} / / \mathrm{dx}$.doi.org/10.1787/9789264214682-en

Olesen, S. (2014). Publishing and Sharing Sensitive Data. Australian National Data Service. Retrieved from http://ands.org.au/guides/sensitivedata.html

Pietkiewicz, I., \& Smith, J. A. (2014). A practical guide to using interpretative phenomenological analysis in qualitative research psychology. Czasopismo Psychologiczne Psychological Journal, 20(1), 7-14. https://doi.org/10.14691/CPPJ.20.1.7

Ross, A. (1999). What is curriculum and why does it matter? In A. Ross (Ed.), Curriculum: Construction and Critique (pp. 8-10). London: Taylor and Francis.

Shenton, A. K. (2004). Strategies for ensuring trustworthiness in qualitative research projects. Education for Information, 22(2), 63-75. https://doi.org/10.3233/EFI-2004-22201

Smith, K. M., Else, F., \& Crookes, P. A. (2013). Engagement and academic promotion: A review of the literature. Higher Education Research \& Development, $\quad 33(4), \quad$ 836-847. https://doi.org/10.1080/07294360.2013.863849

Tilley, S., \& Taylor, L. (2013). Understanding curriculum as lived: teaching for social justice and equity goals. Race Ethnicity and Education, 16(3), 406-429. https://doi.org/10.1080/13613324.2011.645565

Tong, W., \& Jiang, T. (2016). Gaodeng zhiye jiaoyu zhuanye jiaoxue ziyuanke pingtai jianshe yanjiu [Research on construction of professional teaching database in higher vocational education]. Zhongguogaojiaoyanjiu [Chinese Higher Education Research], (1), 107-110.

Van den Berghe, W. (1997). Indicators in perspective. The use of quality Indicators in vocational education and training. Retrieved from https://files.eric.ed.gov/fulltext/ED417351.pdf

Van Manen, M. (1984). Practicing phenomenological writing. Phenomenology and Pedagogy, 2(1), 36-69.

Van Manen, M. (1990). Researching lived experience: human science for an action sensitive pedagogy. New York: State University of New York Press.

Van Manen, M. (2014). Phenomenology of Practice: Meaning-Giving Methods in Phenomenological Research and Writing (Vol. 13). Walnut Creek, CA: Left Coast Press.

Wang, Y. (2010). Construction of tine curriculums in college. Chinese Vocational and Technical Education, (21), $11-13$. 
Yin, K. R. (2009). Case study research design and methods (4th ed.). London, UK: SAGE Publications.

Zhao, Y. (2011). The development situation and countermeasure research on occupational school skills competition (Master's thesis). Retrieved from http://cdmd.cnki.com.cn/Article/CDMD-10285-1012284216.html

\section{Copyrights}

Copyright for this article is retained by the author(s), with first publication rights granted to the journal.

This is an open-access article distributed under the terms and conditions of the Creative Commons Attribution license (http://creativecommons.org/licenses/by/4.0/). 